không thể phẫu thuật được. Đường phẫu thuật rãnh lợi môi qua mũi (hay đường "lột găng") cùng với đường mổ trước tai dưới thái dương sử dụng riêng lẻ hay phối hợp giúp chúng tôi áp dụng được cho đa số các trường hợp u tiến triển rộng vào trong nội sọ.

Mặc dù đã có những kỹ thuât mới được áp dụng nhưng tỷ lệ tái phát sau mổ của u xâm lấn vào sọ vẫn được ghi nhận từ $15-50 \%$. Trong nghiên cứu này chúng tôi chưa gặp tái phát cũng như những biến chứng và tử vong. Cần nhắc lại: nếu một bệnh nhân nam tuổi dậy thì có dấu hiệu nghẹt mũi, chảy máu mũi thì cần sớm được khám bởi các bác sĩ chuyên khoa Tai Mũi Họng.

\section{TÀI LIÊU THAM KHẢO}

1. Snyderman C.H., Pant H.: Endoscopic management of vascular sinonasal tumors, including angiofibroma. Otolaryngol. Clin. North Am., 2016; 49(3): 791-807.

2 Charkaborty S., Ghoshal S., Patil V.M,. Oinam A.S., Sharma S.C.: Conformal radiotherapy in the treatment of advanced juvenile nasopharygeal angiofibro- ma with intracranial extension: an institutional experience. Int. J. Radiation Oncology
Biol. Phys., 2011; 80: 1398-1404.

3. Blount A., O'Riley K., Woodworth B.A.: Juvenile nasopharyngeal angiofibroma. Otolaryngol. Clin. North Am., 2011; 44: 989-1004.

4. Balcerzak J., Gotlib T., Hamera M., OsuchWójcikiewicz E., Niemczyk K.: Angiofibroma juvenile evolution of surgical management. Otolaryngol. Pol. 2011; 65(5 Suppl): 12-16.

5. Danesi G., Panciera D.T., Harvey R., Agostinis C.: Juvenile nasopharyngeal an- giofibroma: evaluation and surgical management of advanced disease. Otola- ryngol Head Neck Surg., 2008; 138: 581-586.

6. Trânn mInh Trường: Môt số kinh nghiệm điều trị phẫu thuật u xơ vòm mũi họng . Tập san Hội nghi KHKT năm 2007 ĐHYD

7. Bales C., Kotapka M., Loevner L.A., Al-Ravi M., Weinstein G. et al.: Craniofacial resection of advanced juvenile nasopharyngeal angiofibroma. Arch. Oto- laryngol. Head. Neck. Surg., 2002; 128: 1071-1078.

8. Schick B., Kahle G.: Radiological findings in angiofibroma. Acta. Radiol., 2000; 41: 585-593.

9. Bales C., Kotapka M., Loevner L.A., Al-Ravi M., Weinstein G. et al.: Craniofacial resection of advanced juvenile nasopharyngeal angiofibroma. Arch. Oto- laryngol. Head. Neck. Surg., 2002; 128: 1071-1078.

\title{
ĐÁNH GIÁ TƯƠ'NG QUAN GIỮA BÊ̂NH COVID-19 VÀ Độ BAO PHỦ TIÊM VẮC XIN Ở TỈNH ĐẮK LẮK, NĂM 2021
}

\author{
Nguyễn Ngọc Như Khuêi , Vũ Thị Quỳnh Hậu², Nguyễn Hữu Huyên ${ }^{3}$
}

\section{TÓM TẮT}

Nghiên cứu này nhằm đánh giá mối tương quan giữa bệnh COVID-19 và độ bao phủ tỷ lệ tiêm vắc xin mũi 1 , mũi 2 tai tỉnh Đắk Lắk. Bằng phương pháp nghiên cứu hồi cứu mô tả có phân tích số liệu thu thập trên các báo cáo nhanh hàng ngày của Sở $Y$ tế Đắk Lắk và báo cáo đô bao phủ tiêm mũi 1 , mũi 2 vắc xin theo huyện, thị xã̃, thành phố. Kết quả cho thấy, không có sự tương quan giữa độ bao phủ tỷ lệ tiêm mũi 1 , mũi 2 vắc xin và số ca mắc mới theo thời gian trước và sau 7,14 và 21 ngày. Không có tương quan giữa độ bao phủ tỷ lệ tiêm mũi 1 , mũi 2 vắc xin và số ca mắc mới theo ngày toàn tỉnh. Có sự tương quan giữa độ bao phủ tỷ lệ tiêm mũi 1 , mũi 2 vắc xin và mức độ bệnh: không triệu chứng và triệu chứng nhẹ. Có tương quan giữa tỷ lệ tiêm vắc xin mũi 1 và số bệnh nhân ra viên theo ngày toàn tỉnh.

Tư khóa: CỎVID-19, Vắc xin, Tương quan, Đắk Lắk.

${ }^{1}$ Bênh viện Đa khoa Vùng Tây Nguyên

${ }^{2}$ Trung Tâm Y tế Thành phố Buôn Ma Thuột

${ }^{3}$ Sở Y tế tỉnh Đăk Lăk

Chịu trách nhiệm chính: Nguyễn Ngọc Như Khuê

Email: nhukhuenguyen@gmail.com

Ngày nhận bài: 16.9.2021

Ngày phản biên khoa hoc: 8.11.2021

Ngày duyệt bài: 22.11.2021

\section{SUMMARY \\ EVALUATE THE CORRELATION BETWEEN COVID-19 DISEASE AND COVERAGE OF VACCINATION RATES IN DAK LAK PROVINCE, 2021}

This study aims to evaluate the correlation between COVID-19 disease and coverage of vaccination rates of 1st and 2nd doses in Dak Lak province. Using retrospective descriptive study with analysis of data collected on daily quick reports of Dak Lak Health Service and reported coverage of 1st and 2nd dose vaccines by district, town, and city. The results showed that there was no correlation between the coverage rate of 1st dose, 2nd dose of vaccine and the number of new cases over time before and after 7, 14 and 21 days. There is no correlation between coverage rate of 1st dose, 2nd dose of vaccine and the number of new cases per day in the province. There is a correlation between the coverage rate of 1st dose, 2nd dose of vaccine and clinical leval of disease: asymptomatic and mild symptoms. There is a correlation between the rate of 1st dose vaccination and the number of patients discharged from hospital by day in the whole province. Lak. 


\section{I. ĐĂT VẤN ĐỀ}

Bệnh COVID-19 là bệnh truyền nhiễm cấp tính thuộc nhóm A do vi rút SARS-CoV-2 gây ra [1]. Vắc xin hiện nay là chiến lược giảm thiểu chính để phòng bênh COVID-19 trên khắp thế giới. Tại Việt Nam, Bộ Y tế đã phê duyêt 8 loại vắc xin gồm: AstraZeneca, Gam-COVID-Vac (tên khác là SPUTNIK V), Vero Cell, Comirnaty của Pfizer/BioNTech, Vắc xin Spikevax (Tên khác là Moderna), vắc-xin Janssen, vắc-xin Hayat-Vax và vắc-xin Abdala [2]. Tính đến sáng ngày 29/11, cập nhật thông tin trên Cổng tiêm chủng COVID19 cho thấy cả nước đã tiêm hơn 120,7 triệu liều vaccine phòng COVID-19 nhưng diến tiến tình dịch COVID-19 trên toàn quốc vần hết sức phức tạp [3].

Tính đến ngày $28 / 11 / 2021$, Đắk Lắk đã ghi nhận 7.570 trường hợp mắc tại $15 / 15$ huyện, thị xã, thành phố; 42 trường hợp tử vong; 5.834 trường hợp hoàn thành điều tri và xuất viện. Toàn tỉnh đã tiêm tổng số liều vắc xin là 1.699.704 liều với tổng số 1.326 .719 đối tượng đích (trên 18 tuổi), trong đó tiêm 1 mũi là 1.209 .363 liều (đạt tỷ lệ là $91,2 \%$ ) và tiêm mũi 2 là 490.341 liêu (đạt tỷ lệ là 37\%) [4]. Chúng tôi nhận thây các trường hợp mắc bệnh tiếp tục gia tăng, tình hình dịch bệnh phức tạp mặc dù tỷ lệ tiêm vắc xin đạt tỷ lệ cao trên toàn quốc cũng như ở tỉnh Đắk Lắk. Do đó, chúng tôi nghiên cứu, tiến hành thực hiện đánh giá mối liên quan giữa thực trạng mắc bệnh COVID-19 và độ bao phủ tiêm vắc xin phòng COVID-19 ở tỉnh Đắk Lắk với mục tiêu: Xác định tương quan giữa số ca mắc mới, số ca ra viện, mức độ bệnh COVID-19 và độ bao phủ tiêm mũi 1 , mũi 2 vắc xin phòng COVID-19 ở tỉnh Đắk Lắk, năm 2021.

\section{II. ĐỐI TƯỢNG VÀ PHƯƠNG PHÁP NGHIÊN CỨU}

2.1. Đối tượng nghiên cứu. Sử dụng số liệu thu thập trên các báo cáo nhanh hàng ngày của Sở Y tế Đắk Lắk thông báo từ ngày $24 / 10 / 2021$ đến ngày $28 / 11 / 2021$ (36 ngày) và báo cáo tình trạng độ bao phủ tiêm vắc xin mũi 1 , mũi 2 vắc xin theo huyện, thị xã, thành phố từ ngày $24 / 10 / 2021$ đến ngày 28/11/2021.

Các số liệu thu thập thông tin gồm có:

- Dân số trung bình theo huyện, tỉnh năm 2021.

- Số ca mắc mới, ra viện và tình trạng mức độ bệnh nhân hàng ngày.

- Độ bao phủ tiêm vắc xin: mũi 1 , mũi 2 theo huyên, tỉnh

2.2. Đia điểm nghiên cứu. Số liêu thu thâp trên địa bàn ở 15 huyện, thị xã, thành phố và chung Toàn tỉnh

2.3. Thời gian nghiên cứu. Từ ngày 24/10/2021 đến 28/11/2021.

\subsection{Phương pháp nghiên cứu}

2.4.1. Cõ mấu: Chúng tôi khảo sát toàn bô báo cáo nhanh 36 ngày của Sở $Y$ tế Đắk Lắk và báo cáo tình trạng độ bao phủ tiêm vắc xin tiêm mũi 1 , mũi 2 vắc xin theo huyện, thị xã, thành phố tữ ngày 24/10/2021 đến ngày $28 / 11 / 2021$.

2.4.2. Thiết kế nghiên cứu: Áp dụng phương pháp nghiên cứu hồi cứu mô tả, phân tích.

2.4.3. Nội dung nghiên cứu. Xác định tương quan giữa số ca mắc mới, số ca ra viện, mức độ bệnh COVID-19 và độ bao phủ tiêm vắc xin mũi 1 , mũi 2 vắc xin.

2.4.4. Phương pháp thu thập và phân tích số liệu. Sử dung bảng tính trên Excel đã được thiết kế sẵn để thu thập dữ liệu.

Kiểm tra tính hợp lệ, logic của số liệu và nhập thông tin vào phần mềm quản lý nhập liệu Epidata 3.1, sử dụng phần mềm SPSS 20.0 để phân tích số liệu.

\section{KẾT QUẢ NGHIÊN CỨU}

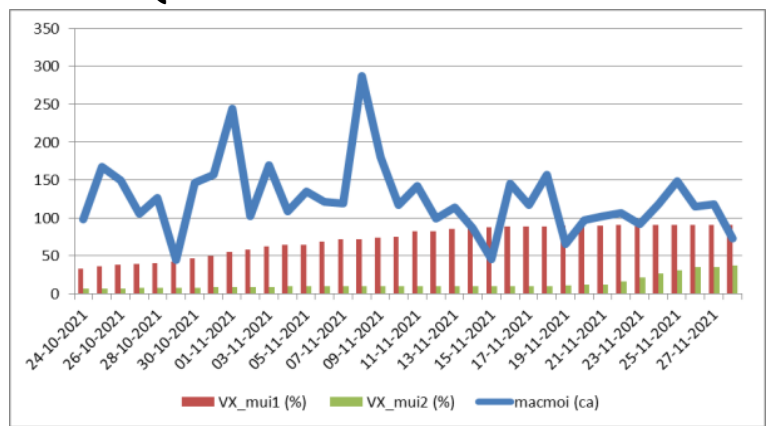

Biếu đồ 1: Mô tả độ bao phủ tỷ lê tiêm vắc xin (mũi 1 và mũi 2) và số ca mắc mới theo ngày trên Toàn tỉnh

Biểu đồ 1 cho thấy đường biểu diễn của ca mắc mới có chiều hướng giảm sau ngày $07 / 11 / 2021$. Tại thời điểm ngày $07 / 11 / 2021$ thì độ bao phủ tiêm vắc xin mũi 1 đạt $71,6 \%$ (ngưỡng tạo ra miễn dịch cộng đồng).

Bảng 1. Phân tích sự tương quan giữa tỷ lệ tiêm vắc xin và số ca mắc mới theo thời gian trước và sau 7,14 và 21 ngày theo đơn vị huyện (Tỷ lệ tiêm vắc xîn mũí 1 và múi 2 được tính từ ngày 7/11/2021)

\begin{tabular}{|c|c|c|c|c|c|}
\hline \multirow{2}{*}{$\begin{array}{c}\text { Tỷ lệ } \\
\text { tiêm vắc xin }\end{array}$} & \multicolumn{5}{|c|}{ Số mắc trên 100.000 dân } \\
\hline & Qua 14 ngày & Qua 7 ngày & Sau 7 ngày & Sau 14 ngày & Sau 21 ngày \\
\hline Mũi 1: r & 0.435 & 0.387 & 0.158 & 0.191 & 0.273 \\
\hline
\end{tabular}




\begin{tabular}{|c|c|c|c|c|c|}
\hline$p$ & 0.105 & 0.154 & 0.574 & 0.496 & 0.325 \\
\hline Mũi 2: r & 0.095 & -0.071 & -0.449 & -0.295 & -0.257 \\
\hline$p$ & 0.735 & 0.802 & 0.093 & 0.287 & 0.356 \\
\hline \multicolumn{6}{|r|}{} \\
\hline
\end{tabular}

Qua bảng 1 cho thấy chưa có sự tương quan giữa tỷ lệ tiêm mũi 1 , mũi 2 vắc xin và số ca mắc mới theo thời gian trước và sau 7,14 và 21 ngày.

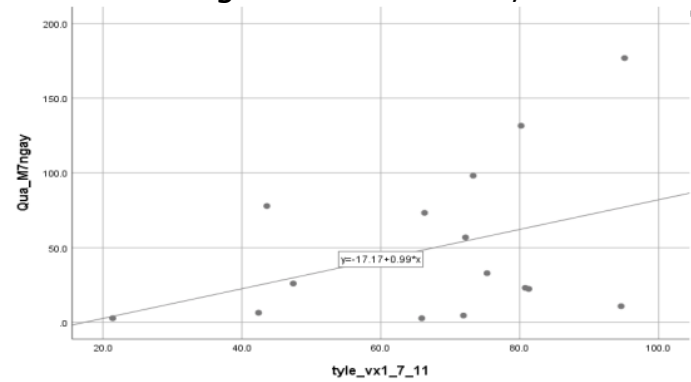

Hình 1: Tỷ lệ tiêm vắc xin mũi 1 với tỷ lệ ca mắc trước 7 ngày

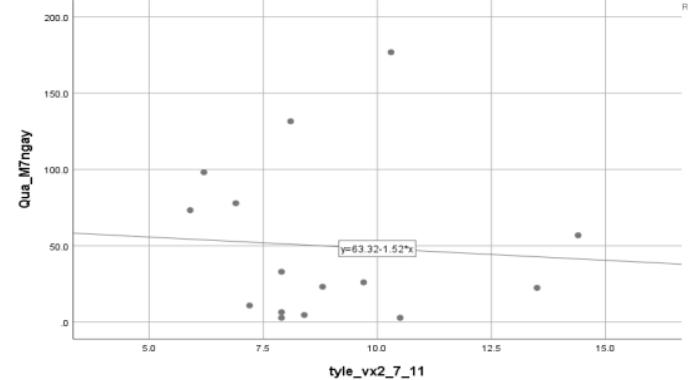

Hình 3: Tỷ lệ tiêm vắc xin mũi 2 với tỷ lệ ca mắc trước 7 ngày

Bảng 2. Phân tích sự tương quan giữa tỷ lệ tiêm vắc xîn và số ca mắc mới theo ngày toàn tỉnh (Tỷ lệ tiêm vắc xin mũi 1 và mũi 2 được tính từ ngày 7/11/2021 toàn tỉnh đạt $71,6 \%)$

\begin{tabular}{|c|c|}
\hline $\begin{array}{c}\text { Tỷ lệ tiêm vắc } \\
\text { xin }\end{array}$ & $\begin{array}{c}\text { Tỷ lệ mắc } \\
\text { mới /100.000 dân }\end{array}$ \\
\hline Mũi 1 & -0.209 \\
\hline$r$ & 0.221 \\
\hline$p$ & -0.166 \\
\hline Mũi 2 & 0.334 \\
\hline$r$ & 0.05 level \\
\hline$p$ & *Correlation is significant at the 0.0 \\
(2-tailed).
\end{tabular}

Qua bảng 2 cho thấy chưa có sự tương quan giữa tỷ lệ tiềm mũi 1 , mũi 2 vắc xin và số ca mắc mới theo ngày toàn tỉnh (Tỷ lệ tiêm vắc xin mũi 1 và mũi 2 được tính từ ngày $7 / 11 / 2021$ toàn tỉnh đạt $71,6 \%$ ).

Bảng 3. Phân tích sự tương quan giữa tý lệ tiêm văc xîn và triệu chứng bệnh theo ngày toàn tỉnh (Tỷ lệ tiêm vắc xin mữi 1 và mũi 2 được tính tữ ngày 7/11/2021 toàn

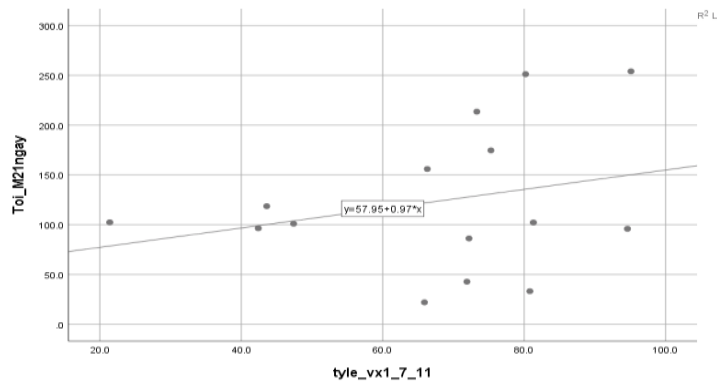

Hình 2: Tỷ lệ tiêm vắc xin mũi 1 với tỷ lệ ca mắc sau 21 ngày

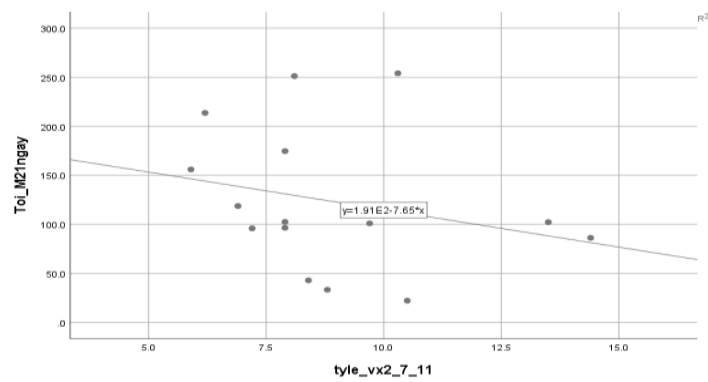

Hình 4: Tỷ lệ tiêm vắc xin mũi 2 với tỷ lệ ca mắc sau 21 ngày

tỉnh đạt 71,6\%)

\begin{tabular}{|c|c|c|c|c|}
\hline \multirow{2}{*}{$\begin{array}{l}\text { Tỷ lệ } \\
\text { tiệm } \\
\text { vắc } \\
\text { xin }\end{array}$} & \multicolumn{4}{|c|}{ Triêu chứng bênh COVID-19 } \\
\hline & $\begin{array}{l}\text { Không } \\
\text { có triệu } \\
\text { chứng }\end{array}$ & $\begin{array}{l}\text { Triệu } \\
\text { chứng } \\
\text { nhe }\end{array}$ & $\begin{array}{c}\text { Mức độ } \\
\text { trung } \\
\text { bình }\end{array}$ & $\begin{array}{l}\text { Mức } \\
\text { độ } \\
\text { năna }\end{array}$ \\
\hline \multicolumn{5}{|c|}{ Tiêm mữi 1} \\
\hline $\mathbf{r}$ & $.701 * *$ & $-.662 * *$ & -0.29 & 0.088 \\
\hline $\mathbf{p}$ & .000 & .000 & 0.086 & 0.608 \\
\hline \multicolumn{5}{|c|}{ Tiêm mũ̃ 2} \\
\hline $\mathbf{r}$ & $672 * *$ & $-.669 * *$ & -0.247 & $.372^{*}$ \\
\hline $\mathbf{p}$ & .000 & .000 & 0.147 & 0.025 \\
\hline \multicolumn{5}{|c|}{$\begin{array}{l}\text { ** Correlation is significant at the } 0.01 \text { level } \\
\text { (2-tailed). }\end{array}$} \\
\hline \multicolumn{5}{|c|}{$\begin{array}{c}* \text { Correlation is significant at the } 0.05 \text { level } \\
\text { (2-tailed). }\end{array}$} \\
\hline
\end{tabular}
tiêm mũi 1 , mũi 2 vắc xin và mức độ bệnh: Không triệu chứng $(r=0.701 ; p=0,000)$, triệu chứng nhẹ $(r=0.662 ; p=0,000)$ với tỷ lệ tiêm vằc xin mũi 1 và không triệu chứng $(r=0.672$; $p=0,000)$, triệu chứng nhẹ $(r=0.669 ; p=0,000)$ với tỷ lệ tiêm vắc xin mũi 2 . Chưa thấy sự tương quan giữa độ bao phủ tiêm vắc xin và mức độ trung bình và mức độ nặng của bệnh. 


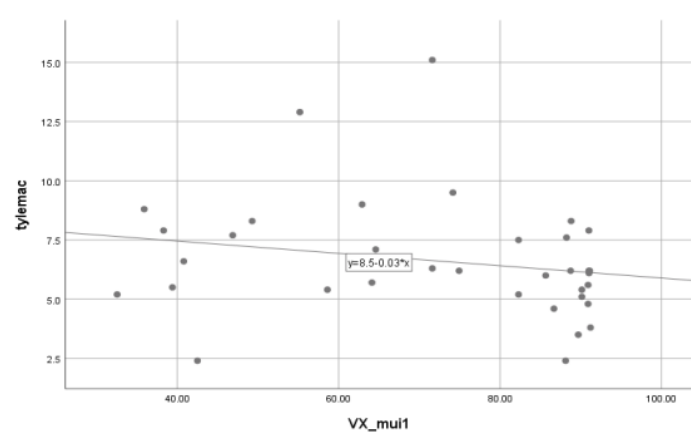

Hình 5: Tỷ lệ tiêm vắc xin mũi 1 với tỷ lệ ca mắc theo ngày

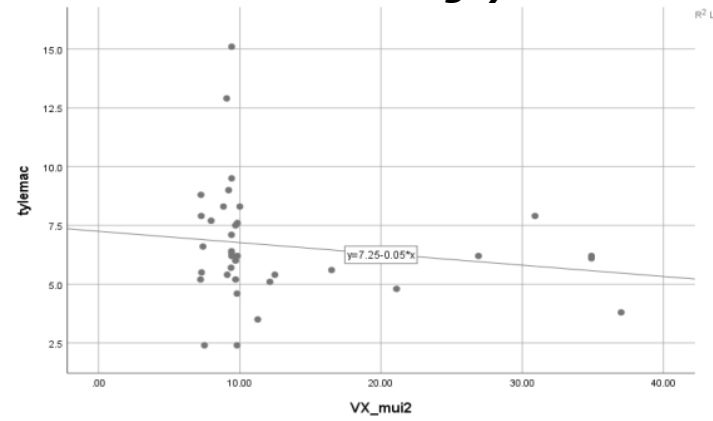

Hình 6: Tỷ lệ tiêm vắc xin mũi 2 với tỷ lệ ca mắc theo ngày

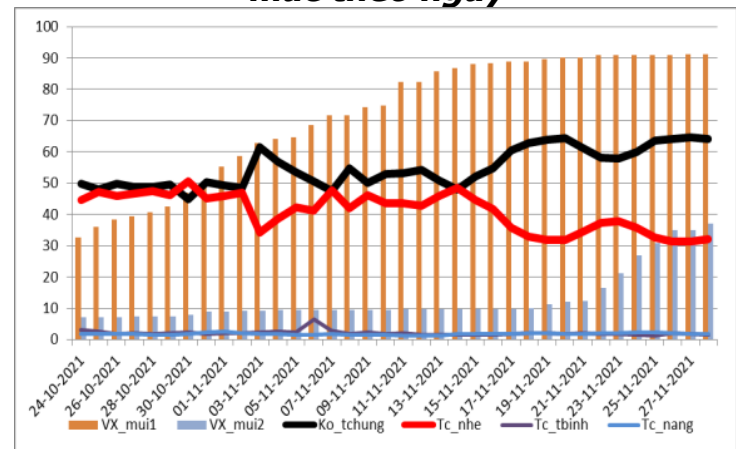

Biểu đồ 2. Mô tả tỷ lệ tiêm vắc xin và triệu chứng bệnh theo ngày toàn tỉnh

Bảng 4. Phân tích sứ tương quan giữa tý lệ tiêm vắc xîn và số bệnh nhân ra viện theo ngày toàn tỉnh (Tỷ lề tiêm vắc xin mũi 1 và mũi 2 được tính từ ngày 7/11/2021 toàn tinh dat $71,6 \%$ )

\begin{tabular}{|c|c|}
\hline Tý lệ tiêm văc xin & Số bệnh nhân ra viện \\
\hline \multicolumn{2}{|c|}{ Mũi 1 } \\
\hline$r$ & \multicolumn{2}{|c|}{0.540} \\
\hline$p$ & 0.001 \\
\hline \multicolumn{2}{|c|}{ Mũi 2 } \\
\hline p & -0.139 \\
\hline & 0.821 \\
\hline
\end{tabular}
tailed).
Bảng 4 cho thấy có tương quan giữa tỷ lệ tiêm vắc xin mũi 1 và số bệnh nhân ra viện theo ngày toàn tỉnh $(r=0.540 ; p=0,001)$. Không có sư tương quan giữa tỷ lề tiêm vắc xin mũi 2 và số bệnh nhân ra viện theo ngày toàn tỉnh $(r=0$. $0.139 ; p=0,821$ ).

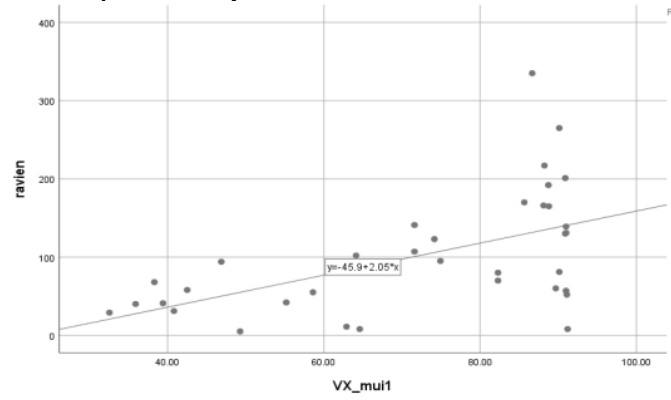

Hình 8. Phân tích sự tương quan giữa tỷ lệ tiêm vắc xîn mûí 1 và số ca ra viện theo ngày toàn tỉnh

\section{BÀN LUÂN}

Tiêm chủng COVID-19 giúp giảm nguy cơ mắc COVID-19 và những biến chứng tiêm ẩn nghiêm trọng của căn bệnh này [5]. Qua phân tích số liệu thu thập trên các báo cáo nhanh hàng ngày của Sở $Y$ tế Đắk Lắk và báo cáo độ bao phủ tiêm vắc xin mũi 1 , mũi 2 vắc xin theo huyện, thị xã, thành phố, chúng tôi nhận thấy không có sự tương quan giữa tỷ lê tiêm mũi 1 , mũi 2 vắc xin và số ca mắc mới theo thời gian trước và sau 7,14 và 21 ngày. Đồng thời, qua phân tích dữ liệu trên toàn tỉnh Đắk Lấk cho thây không có tương quan giữa tỷ lệ tiêm mũi 1 , mũi 2 vắc xin và số ca mắc mới theo ngày toàn tỉnh. Mốc thời gian tính từ dữ liệu tỷ lệ tiêm vắc xin mũi 1 vào ngày $7 / 11 / 2021$ toàn tỉnh đạt $71,6 \%$. Theo báo cáo của Bộ Y tế Israel thì hiệu quả của 2 liều vắc xin BNT162b2 (Pfizer-BioNTech) để phòng mắc bệnh COVID-19 chỉ là 39\% thấp hơn trên thử nghiệm lâm sàng là $96 \%$ [6]. Kết quả nghiên cứu của chúng tôi cũng phù hợp với nghiên cứu tại 68 Quốc gia và 2.947 Quận của Mỹ đã cho thấy kết quả tương đồng dường như không có mối quan hệ liên quan rõ ràng giữa tỷ lệ phần trăm dân số được tiêm vắc xin đây đủ và các trường hợp COVID-19 mới trong 7 ngày qua [7].

Các nghiên cứu về tính hiệu quả của vắcxin cho thây bằng chứng đáng tin cậy rằng các vắc-xin COVID-19 mRNA đem lại mức độ bảo vê tương tự trong điều kiện thực tế như trong môi trường thử nghiệm lâm sàng, giúp làm giảm hơn 90 phần trăm nguy cơ mắc COVID-19, bao gồm cả bệnh nghiêm trọng với những người đã được tiêm vắc-xin đầy đủ [6]. Nhưng trên thực tế đến 
ngày 28/11/2021 ở tỉnh Đắk Lắk đã nhận được 13 đợt cấp vắc xin với 2.034.448 liều từ Bộ Y tế (Trong đó: AstraZeneca: 712550 liều, Comirnaty Pfizer: 460.338 liêu, Mordena: 61.320 liều và Verocell Sinopharm: 800.240 liều) nên hiệu quả bảo vệ đạt được sau tiêm các loại vắc xin là khác nhau [4]. Mặc dù các vắc xin COVID-19 hiệu quả, một số người đã tiêm đủ liều để phòng COVID-19 vẫn sẽ mắc bệnh, vì không có vắc-xin nào hiệu quả $100 \%$. Những trường hợp này được gọi là ca đột phá vắc-xin. Tuy nhiên, dữ liệu chỉ ra rằng vắc-xin có thể giúp một số triệu chứng bớt nghiêm trọng hơn ở những người đã được tiêm chủng nhưng vẫn mắc COVID-19 [6]. ở bảng 3 cho thấy có mối liên quan tỷ lệ tiêm mũi 1 , mũi 2 vắc xin và mức độ bệnh: không triệu chứng $(r=0.701 ; p=0,000)$, triệu chứng nhẹ $(r=0.662 ; p=0,000)$ với tỷ lệ tiêm vắc xin mũi 1 và không triệu chứng $(r=0.672 ; p=0,000)$, triệu chứng nhe $(r=0.669 ; p=0,000)$ với tỷ lệ tiêm vắc xin mũi 2 . Không có mối liên quan về mức độ trung bình và mức độ nặng của bệnh COVID19 với tỷ lệ tiêm vắc xin. Điều này cũng phù hợp với kết quả nghiên cứu tại Mỹ, mặc dù tỷ lệ tiêm chủng giúp bảo vệ các cá nhân chống lại tình trạng bệnh COVID-19 nhập viện và tử vong. Trung tâm Kiểm soát bệnh tật Mỹ báo cáo sự gia tăng từ 0,01 đến $9 \%$ và 0 đến $15,1 \%$ (từ tháng 1 đến tháng 5 2021) về tỷ lệ nhập viện và tử vong, tương ứng, trong số những người được tiêm vắc xin đầy đủ [8]. Những phát hiện này phù hợp với việc giảm thiểu rủi ro trong số các ca nhiễm đột phá bằng vắc xin so với trường hợp không tiêm vắc xin [9]. Kết quả này của chúng tôi cũng phù hợp với thang đánh giá tiến triển lâm sàng COVID-19 của Tổ chức $Y$ tế Thế giới, mức độ nghiêm trọng của bệnh cao nhất trong số các trường hợp nhiễm đột phá COVID-19 bằng vắc xin thấp hơn đáng kể so với các trường hợp không được tiêm chủng $(\mathrm{aOR}, 0,36$; $\mathrm{KTC}$ $95 \%, 0,25-0,51$ ) [9].

Kết quả nghiên cứu của chúng tôi cho thấy có tương quan giữa tỷ lệ tiêm vắc xin mũi 1 và số bệnh nhân ra viện theo ngày toàn tỉnh $(r=0.54$; $\mathrm{p}=0,001)$. Không có sự tương quan giữa tỷ lệ tiêm vắc xin mũi 2 và số bệnh nhân ra viện theo ngày toàn tỉnh $(r=0 .-0.139 ; p=0,821)$.

\section{KẾT LUÂ̂N}

- Không có sự tương quan giữa độ bao phủ tỷ lệ tiêm mũi 1 , mũi 2 vắc xin và số ca mắc mới theo thời gian trước và sau 7,14 và 21 ngày. Không có tương quan độ bao phủ tỷ lệ tiêm mũi 1 , mũi 2 vắc xin và số ca mắc mới theo ngày toàn tỉnh.

- Có sự tương quan tỷ lệ tiêm mũi 1, mũi 2 vắc xin và mức độ bệnh: Không triệu chứng $(r=0.701 ; p=0,000)$, triệu chứng nhe $(r=0.662$; $\mathrm{p}=0,000)$ với tỷ lệ tiêm vắc xin mũi 1 và không triệu chứng $(r=0.672 ; p=0,000)$, triệu chứng nhẹ $(r=0.669 ; p=0,000)$ với tỷ lệ tiêm vắc xin mũi 2 . Không có sự tương quan về mức độ trung bình và mức độ nặng của bệnh.

- Có tương quan giữa tỷ lệ tiêm vắc xin mũi 1 và số bệnh nhân ra viện theo ngày toàn tỉnh $(r=0.54 ; p=0,001)$. Không có tương quan giữa tỷ lệ tiêm vắc xin mũi 2 và số bệnh nhân ra viện theo ngày toàn tỉnh $(r=0 .-0.139 ; p=0,821)$.

\section{KIẾN NGH!}

Bên cạnh vai trò của vắc xin, thực trạng mắc COVID-19 trên địa bàn tỉnh còn phụ thuộc rất nhiều vào các thực hành phòng ngừa lây truyền SARS-CoV-2 của cá nhân và cộng đồng. Việc chưa thấy có sự tương quan giữa độ bao phủ của vắc xin COVID-19 và số mắc mới nhấn manh tầm quan trọng của các thực hành phòng chống dịch. Trong thời gian tới, đích tác động chúng ta cần tập trung kiểm soát chính là thực hiện nghiêm các biện pháp phòng chống dịch bệnh bao gồm các khuyến cáo $5 K$ theo hướng dẫn Bộ $Y$ tế để hạn chế nguy cơ nhiễm bệnh, bảo đảm sức khỏe cho bản thân, gia đình và cộng đồng.

\section{TÀI LIỆU THAM KHẢO}

1 Bô Y tế. Quyết đinh số 3638/QĐ-BYT ngày 30 tháng 07 năm 2021 của Bộ $Y$ tế vê việc ban hành "hướng dấn tạm thời giám sát và phìng, chống COVID-19".

2 Trung tâm Kiểm soát bệnh tật Thành phố Hồ Chí Minh. 8 loại vắc-xin phòng COVID-19 đã được cấp phép tại Việt Nam. https://hcdc.vn/category/van-de-suc-

khoe/covid19/tai-lieu-truyen-thong/8-loai-vacxinphong-covid19-da-duoc-cap-phep-tai-viet-nam27092973b1ad3fac17d53891de8b274f.html. Truy cập ngày $28 / 11 / 2021$.

3 Bộ Y tế. Cổng thông tin của Bộ Y tế về đại dich COVID-19. Việt Nam vượt mốc tiêm 120 triệu liểu; 36 tỉnh, thành đã tiêm vaccine phòng COVID-19 cho trẻ từ 12-17 tuổi. https://covid19.gov.vn/vietnam-vuot-moc-tiem-120-trieu-lieu-36-tinh-thanhda-tiem-vaccine-phong-covid-19-cho-tre-tu-12-17tuoi-171211129100853036.htm. Truy cập ngày 29/11/2021. Truy câp ngày 29/11/2021.

4 Sở Y tế Đắk Lắk. Báo cáo nhanh số 781/BC-SYT ngày 29/11/2021 của Sở Y tế Đắk Lắk về tình hình phòng, chống dịch COVID-19 trên địa bản tỉnh Đắk Lắk.

5 Trung tâm Kiểm soát bênh tật. Vắc-xin COVID-19 có hiệu quả. https://vietnamesè.cdc.gov/ coronavirus/ 2019-ncov/vaccines/ effectiveness/work.html. Truy cập ngày $30 / 11 / 2021$. 
6. Ministry of Health Israel. Two-dose vaccination data. Government of Israel; 2021. https://www.gov.il/BlobFolder/reports/vaccineefcacy-safety-follow-upcommittee/he/fles publications corona_twodose-vaccination-data.pdf. Truy cập ngày $30 / 11 / 2021$.

7 S. V. Subramanian. Akhil Kumar. Increases in COVID-19 are unrelated to levels of vaccination across 68 countries and 2947 counties in the United States. https://link.springer.com/ article/10.1007/s10654-021-00808-7. Truy cập ngày 29/11/2021.
8. McMorrow M. (rep.). Improving communications around vac cine breakthrough and vaccine efectiveness. 2021. Retrieved from https://contextcdn.washingtonpost.com/notes/prod/default/ documents/8a726408-07bd-46bd-a9453af0ae2f3c37/note/57c98 604-3b54-44f0-8b44b148d8f75165. Truy cập ngày 30/11/2021.

9 Mark

w. Tenforde, Wesley H. Self, Katherine Adams. Association Between mRNA Vaccination and COVID-19 Hospitalization and Disease Severity. https://jamanetwork. com/journals/jama/fullarticle/2786039. Truy cập ngày $30 / 11 / 2021$.

\section{KẾT QUẢ QUẢN LÝ, ĐIỀU TRI NGƯờI BÊNNH BỊ TĂNG HUYẾT ÁP TẠI TRUNG TÂM Y TẾ HUYẾN GÒ CÔNG TÂY, TỈNH TIỀN GIANG GIAI ĐOẠN 2019 - 2020}

\section{TÓM TẮT}

Đắt vấn đề: Điều trị Tăng huyết áp (THA) là công việc liên tục và lâu dài nên viêc quản lý và điêu trì người bệnh THA là hết sức cần thiết. Mục tiêu: Đánh giá kết quả quản lý điều trị người bệnh THA và phân tích một số yếu tố ảnh hưởng đến kết quả quản lý điều trị THA tại Trung tâm y tế huyện Gò Công Tây từ năm 2019- 2020.Phương pháp: Ṅghiên cứu mô tả cắt ngang kết hợp giữa định lượng và định tính dựa trên cơ sở thu thập thông tin từ phần mềm quản lý, phỏng vấn sâu cán bộ y tế và thảo luận nhóm bệnh nhân THA được quản lý tại TTYT huyện Gò Công Tây từ tháng 4 đến tháng 10/2021.Kết quả: Số người mắc THA được khám và điêu tri ngày càng tăng hàng năm, tỉ lệ người bệnh đi tái khám đúng lịch là $63,6 \%$. Tỉ lệ người bệnh dùng thuốc đúng liều là $89,3 \%$. Kết điêu trị có $28,9 \%$ đối tượng đạt huyết áp mục tiêu. Các chính sách, quy định về quản lý và điêu trị THA, sự thiếu hưt nhân lực, hạn chế về trang thiết bị, cơ sớ vầt chất và thuốc của TYYT, không có nguồn kinh phí hoạt động, cùng các yếu tố cá nhân của người bệnh là những yếu tố ảnh hưởng đến công tác quản lý điều trị THA. Kết luận: Tỷ lệ bệnh nhân đạt huyết áp mục tiêu còn khá thấp $(28,9 \%)$, có nhiều yếu tố từ phía cớ sở y tế và người bệnh ảnh hưởng đến công tác quản lý, điều trị THA.

Từ khóa: Tăng huyết áp, huyết áp mục tiêu, quản lý, điều trị, Gò Công Tây.

\section{SUMMARY \\ ASSESSMENT OF THE RESULTS OF THE TREATMENT MANAGEMENT OF PERSONS WITH}

\footnotetext{
${ }^{1}$ Trung tâm Y tế huyện Gò Công Tây,

2Trường Đai hoc Y tề công cộng

Chịu trách nhiệm chính: Phạm Văn Quang

Email: quangphamgct1965@gmail.com

Ngày nhận bài: 20.9.2021

Ngày phản biên khoa hoc: 12.11.2021

Ngày duyệt bài: 23.11.2021
}

Phạm Văn Quang1, Trần Quốc Lâm²

\section{HIGH BLOOD PRESSURE AT THE HEALTH CENTRAL OF GO CONG TAY DISTRICT, TIEN GIANG PROVINCE FOR 2019 - 2020}

Background: Treatment of hypertension is a continuous and long-term work, so the management and treatment of hypertensive patients is essential. Objectives: Evaluation of the results of management and treatment of hypertension patients and analysis of some factors affecting the results of treatment and management of hypertension at Go Cong Tay District Medical Center from 2019 to 2020. Methods: A crosssectional descriptive study combining quantitative and qualitative based on information collection from management software, in-depth interviews with medical staff and group discussion of hypertensive patients managed at the Go Cong Tay district health center from April to October 2021.Results: The number of people with high blood pressure being examined and treated is increasing every year, the rate of patients coming back for follow-up examination on schedule is $63.6 \%$. The rate of patients taking the correct dose was $89.3 \%$. As a result of treatment, $28.9 \%$ of subjects reached the target blood pressure. Policies and regulations on management and treatment of hypertension, shortage of human resources, limitations on equipment, facilities and drugs of $\mathrm{CHS}$, no operating funding, and personal factors of patients are factors affecting the management of hypertension treatment.Conclusion: The percentage of patients reaching the target blood pressure is still quite low, there are many factors from the medical facilities and the patients that affect the management and treatment of hypertension.

Keywords: Hypertension, target blood pressure, management, treatment, Go Cong Tay.

\section{I. ĐĂT VẤN ĐỀ}

Tăng huyết áp là bệnh mạn tính, đòi hỏi người bệnh phải kiên trì điều trị và tuân thủ chế độ điều trị nếu không sẽ có thể mắc nhiều biến 